play' by patient". Other disadvantages mentioned were the risk of creating dependence, possible duplication of effort and therefore poor use of scarce resources. Several GPs felt that they themselves could have dealt with some problems more effectively. However, 13 GPs said they perceived no disadvantages. Of the GPs, 20 specifically mentioned immediate access and speed of response as advantages. Other advantages mentioned were improved communication, the ready availability of advice, and the confidentiality of the service.

\section{Comment}

The service appeared to fulfil a need and its use by clients and referrers was increasing. From the number of clients who were admitted directly to hospital, and from the level of threatened or actual self-harm, one might expect that many of these clients would previously have been seen urgently on domiciliary visits by a psychiatrist and this was reflected in a reduction in the number of requested domiciliary visits, (79, compared with 125 for the preceding 12 months).

The finding that $78 \%$ of clients had previous contact with mental health services is in accord with a recent study of self-referrals to the Mental Health Advice Centre in Lewisham (Boardman \& Bouras, 1989). These figures may change as the service is more widely publicised. A further project to assess consumer satisfaction is under way.

\section{Acknowledgements}

I wish to express appreciation to the members of Southsea Mental Health Team for their co-operation with this study. I also wish to thank Dr Jennifer Hughes for her helpful advice and Dr Elizabeth King for assistance with computerised data analysis.

\section{References}

Boardman, A. P. \& Bouras, N. (1989) Self-referrals to a community psychiatric clinic. Psychiatric Bulletin, 13, 490-491.

ScoTT, R. D. (1980) A family oriented psychiatric service to the London Borough of Barnet. Health Trends, 12, 65-68.

SMITHIEs, J. M. A. (1986) A psychiatric emergency clinic. Bulletin of the Royal College of Psychiatrists, 10,357-359.

\title{
Your supported lodgings
}

\section{E. Robson, Registrar in Psychiatry, Coney Hill Hospital, Coney Hill, Gloucester GL4 7QJ}

Supported lodgings are an important means of achieving the successful rehabilitation and resettlement of the chronically mentally ill into the community (Anstee, 1978, 1985). In a survey of 15 psychiatric hospitals in England and Wales, it was estimated that $9.3 \%$ of the long-stay patients (i.e. in-patients from one to five years) under 65 years of age were ideally suited to less supervised accommodation outside the hospital. In Gloucestershire the Supported Lodging Scheme is provided by the Psychiatric Social Services Department. It was started to enable 'new' and 'old' long-stay patients at Coney Hill and Horton Road hospitals to be settled in the community. Now any psychiatric or mentally handicapped patient can also enter the scheme if appropriate.
The lodgers had often spent a long period in hospital before placement which, together with their illness, may have diminished their life skills. It has been helpful to provide new lodgers with an explanatory booklet called Your Supported Lodgings, giving guidance not only on the supported lodgings but on other community services and how to use them. This booklet contains the following information and is completed by the supported lodgings officer with each patient before discharge.

The address is given of the supported lodgings and the name of the landlord/landlady, who must provide bed, breakfast, and evening meal Monday to Friday, plus full board Saturday, Sunday and Bank Holidays, together with washing facilities. Lodgers must stick to the house rules, especially those on 
hygiene and smoking. They are advised on the procedure for leaving the lodgings if they so wish.

Details of the members of the rehabilitation team are given under Medical Information. The team consists of a consultant psychiatrist, a community psychiatric nurse, a supported lodgings officer, a social worker and a community occupational therapist. Details of the GP, dentist, chiropodist, optician, and family planning clinic are also given.

There is a section on Money Matters which gives the following information.

(a) The DSS Office responsible for weekly payments.

(b) The lodger's entitlement to weekly rent money, a week day midday meal allowance and pocket money provided he/she has a current certificate of unfitness to work or continues to 'sign on' unemployed.

(c) Patients' fares to and from hospital or day centres can be refunded.

(d) The financial implications of admission to hospital. The lodger is reminded that he must notify the DSS, that he must continue to pay the landlord/landlady a retainer fee of $80 \%$ of the total rent which the DSS will pay for up to eight weeks. While in hospital he receives a small amount of pocket money.

A section on useful addresses and telephone numbers includes those of the local Post Office, chemist, GP, day centre, social club or 'drop in' centre, together with opening times.

Under Transport, useful information about bus timetables and how to use public transport is provided, together with the cheapest times to travel.

Finally, under Leisure Activities, local amenities are detailed with advice to seek additional information at the local library.

\section{Further information}

Supported lodgings in the British Isles have been used to produce accommodation since the 1960s for patients who are less capable and independent and therefore needing more supervision than those in group homes.

The most famous and longest established boarding out scheme is at the town of Gheel in Belgium. In 1960 the mental hospital cared for 200 in-patients and there were 2,600 patients in family care.

The Mental Health Acts of 1959 and 1983 required the local authority "to provide residential accommodation for mentally disordered persons, either directly or with other authorities and/or voluntary organisations or by boarding out".

The National Health Service and Public Health Act 1968 enabled the County Council to finance boarding out schemes.
Typical lodgers are more often male and over 40 years of age; schizophrenia is the most common diagnosis. Such patients often do better living in a household with a carefully selected landlady than with a near relative who may show high emotional involvement (Vaughan \& Leff, 1976). Patients can regain their self-esteem and have the security of a home. Lodgers need careful assessment by the rehabilitation team of their ability to cope in supported lodgings. They must be able to attend to their personal hygiene, use public transport, be willing to pay the rent and be stabilised on a minimum of medication. They have to be registered with a GP on leaving hospital. Particular attention is paid to patients' wishes, background and interests, to their previous home address and the location of their friends and relatives.

The supported lodgings officer selects and interviews potential landlords/ladies, assesses their motivation, inspects the lodgings regularly, organises the complicated finances and gives the landladies support. The landladies offer bed and breakfast and an evening meal on weekdays, full board on weekends and on public holidays, laundry and cleaning services, heating and regular baths. They sign a contract agreeing to these conditions and also to encourage the lodger to make social contacts outside the lodgings, often with the help of a nearby day or 'drop in' centre.

In Gloucester the Supported Lodgings Scheme caters for 130 residents in 30 supported lodgings. The type of lodgings varies from 'foster care' with up to three residents with the landlady in her own home, or a large family home of more than three residents in the landlady's own home, and larger communal homes where residents share the facilities of a house and the landlady is responsible for meals. The number of lodgings and residents have remained almost constant for the past two years and most of the former long-stay patients suitable for lodgings are now living in the community. The booklet Your Supported Lodgings provides the residents with a helpful guide encouraging them to make the most of their regained access to public facilities. The widespread use of similar guide books is recommended so that once back in the community former patients can actually play an active part in it.

\section{References}

ANSTEE, B. H. (1985) An alternative form of community care for the mentally ill. Supported lodgings scheme - a personal view. Health Trends, 17, 39-40.

- (1978) An alternative to group homes. British Journal of Psychiatry, 132, 365-370.

VAughan, C. E. \& LeFF, J. P. (1976) The influence of family and social factors on the course of psychiatric illness. A comparison of schizophrenic and depressed neurotic patients. British Journal of Psychiatry, 129, 125-137. 